\title{
Erratum to "Optimal Hemodialysis Prescription: Do Children Need More Than a Urea Dialysis Dose?”
}

\author{
Michel Fischbach, ${ }^{1}$ Ariane Zaloszyc, ${ }^{1}$ Betti Schaefer, ${ }^{2}$ and Claus Peter Schmitt ${ }^{2}$ \\ ${ }^{1}$ Nephrology Dialysis Transplantation Children's Unit, University Hospital Hautepierre, Avenue Molière, 67098 Strasbourg, France \\ ${ }^{2}$ Division of Pediatric Nephrology, Center for Pediatric and Adolescent Medicine, INF 430, 69120 Heidelberg, Germany \\ Correspondence should be addressed to Michel Fischbach, michel.fischbach@chru-strasbourg.fr \\ Received 15 November 2011; Accepted 15 November 2011 \\ Copyright (C) 2011 Michel Fischbach et al. This is an open access article distributed under the Creative Commons Attribution \\ License, which permits unrestricted use, distribution, and reproduction in any medium, provided the original work is properly \\ cited.
}

All the authors' names were reversed. We would like to correct the author's names to be as follows:

Michel Fischbach instead of Fischbach Michel,

Ariane Zaloszyc instead of Zaloszyc Ariane,

Betti Schaefer instead of Schaefer Betti,

Claus Peter Schmitt instead of Schmitt Claus Peter. 


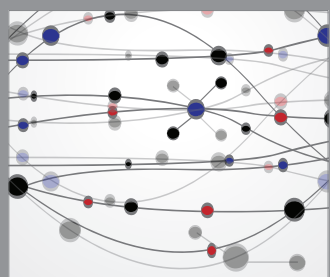

The Scientific World Journal
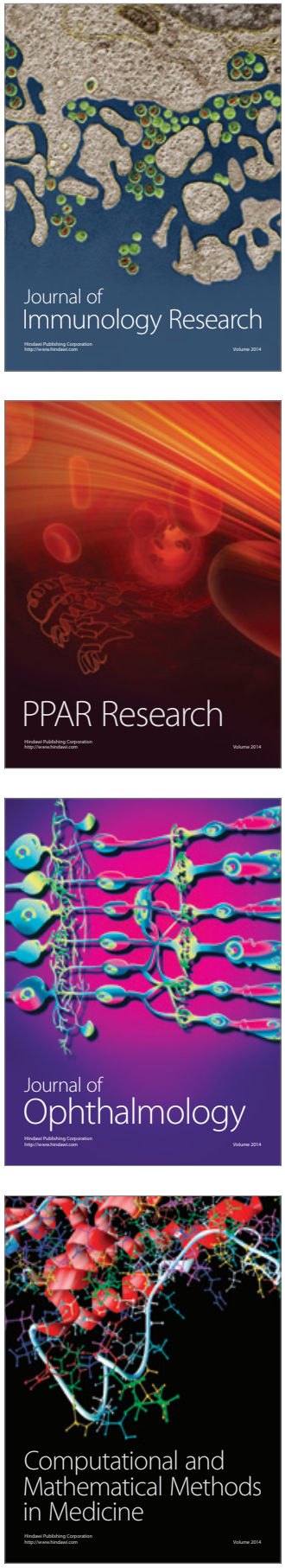

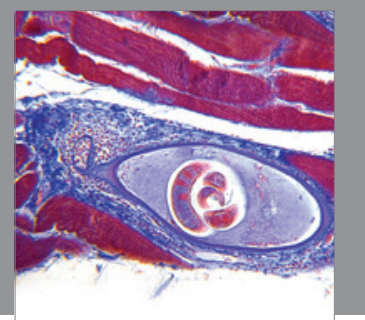

Gastroenterology

Research and Practice
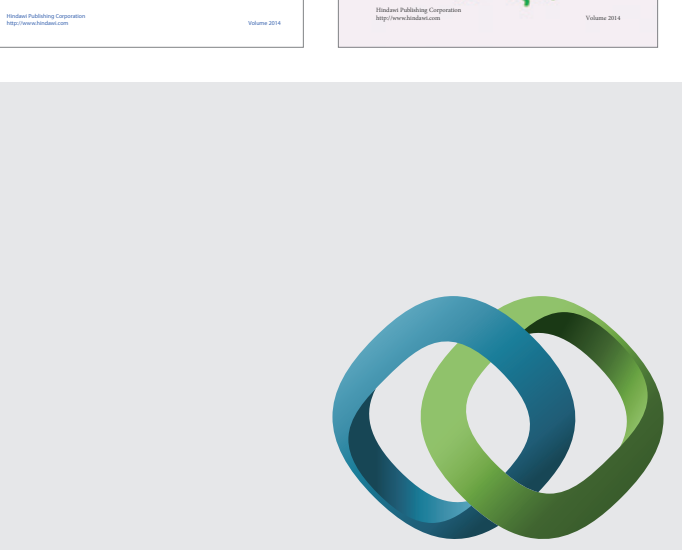

\section{Hindawi}

Submit your manuscripts at

http://www.hindawi.com
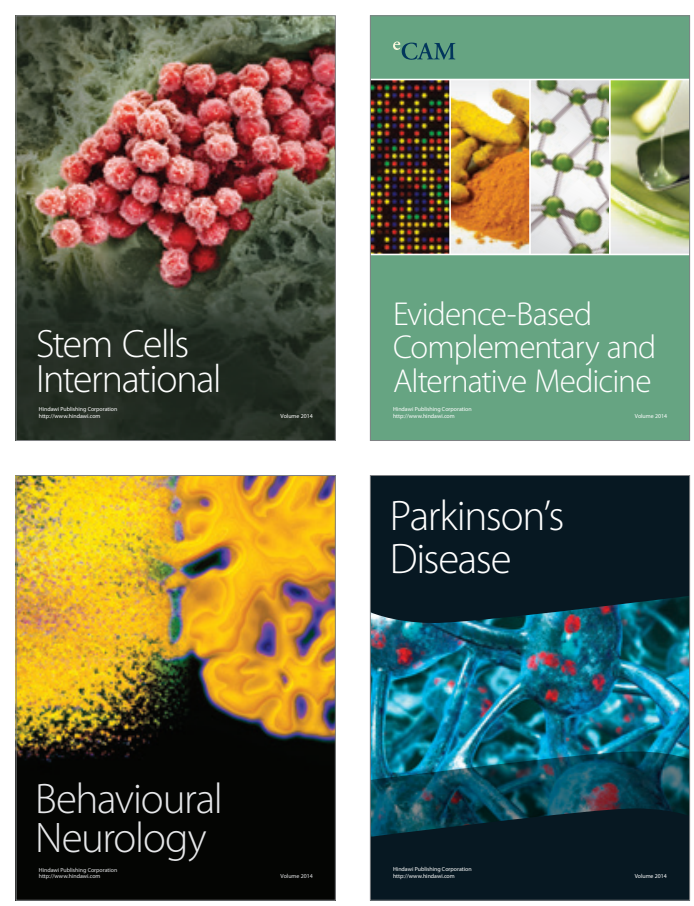

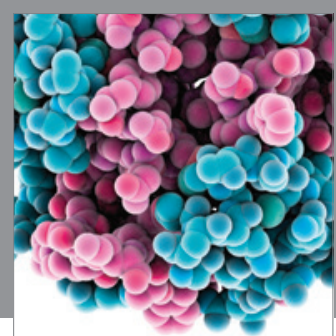

Journal of
Diabetes Research

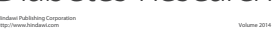

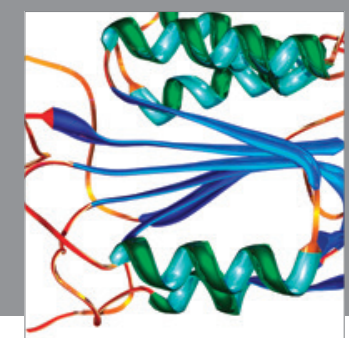

Disease Markers
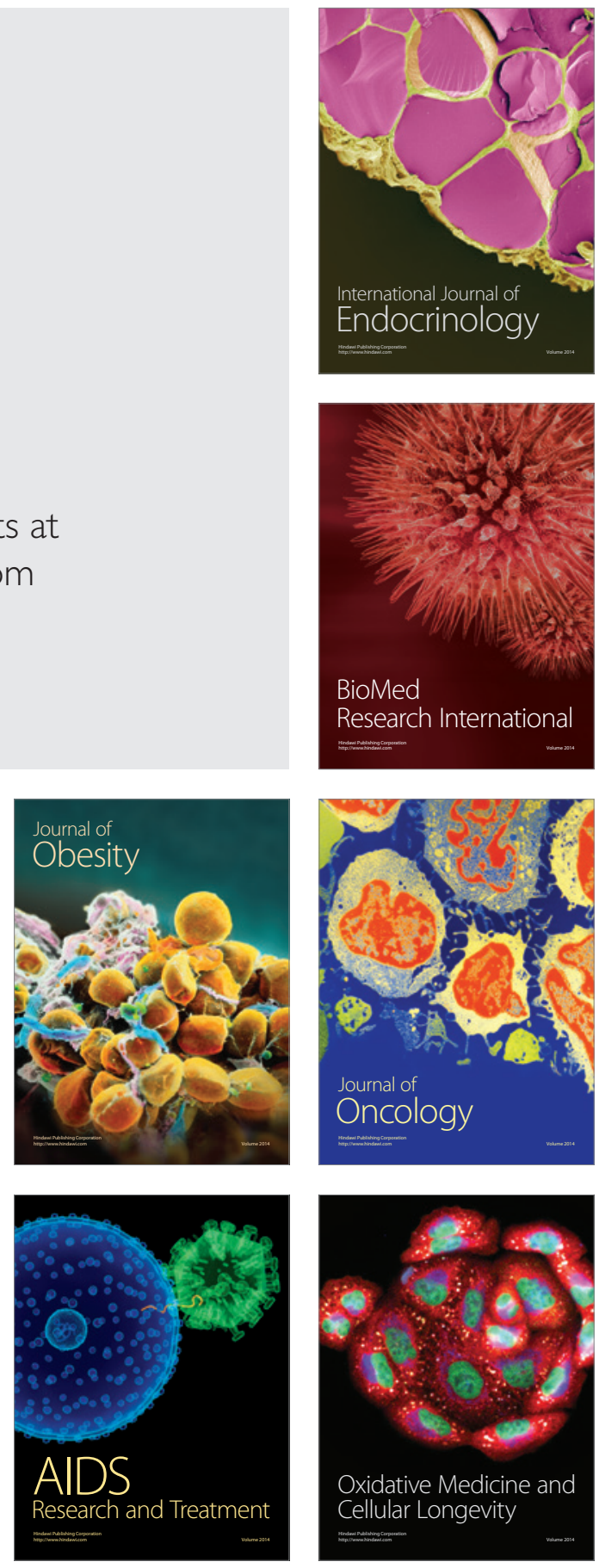